\title{
Systematization of analytical studies of polycythemia vera, essential thrombocythemia and primary myelofibrosis, and a meta-analysis of the frequency of JAK2, CALR and MPL mutations: 2000-2018
}

\author{
Mónica Mejía-Ochoa ${ }^{1}$, Paola Andrea Acevedo Toro ${ }^{2}$ and Jaiberth Antonio Cardona-Arias ${ }^{3 *}$
}

\begin{abstract}
Background: Research into Philadelphia-negative chronic myeloproliferative neoplasms is heterogeneous. In addition, no systematization of studies of polycythemia vera (PV), essential thrombocythemia (ET) or primary myelofibrosis (PMF) have been carried out. The objective of this review is to characterize studies on BCR-ABL1negative chronic myeloproliferative neoplasms and to compare the frequency of JAK2, MPL and CALR mutations in $P V, E T$ and PMF.

Method: A systematic review of the scientific literature was conducted, as was meta-analysis with an ex-ante selection of protocol, according to phases of the PRISMA guide in three interdisciplinary databases. To guarantee reproducibility in the pursuit and retrieval of information, the reproducibility and methodological quality of the studies were evaluated by two researchers.

Results: Fifty-two studies were included, the majority having been carried out in the United States, China, Brazil and Europe. The frequency of the JAK2V617F mutation ranged from 46.7 to $100 \%$ in patients with PV, from 31.3 to $72.1 \%$ in patients with ET, and from 25.0 to $85.7 \%$ in those with PMF. The frequency of the MPL mutation was $0 \%$ in PV, from 0.9 to $12.5 \%$ in ET, and from 0 to $17.1 \%$ in PMF. The CALR mutation occurred at a frequency of $0.0 \%$ in PV, whereas in ET, it ranged from 12.6 to 50\%, and in PMF, it ranged from 10 to 100\%. The risk of this mutation presenting in PV is 3.0 times that found for ET and 4.0 times that found for PMF.

Conclusion: Given the specificity and reported high frequencies of the JAK2V617F, MPL and CALR mutations in this group of neoplasms, the diagnosis of these diseases should not be made on clinical and hematological characteristics alone but should include genetic screening of patients.
\end{abstract}

Keywords: Myeloproliferative disorders, Mutation, Polycythemia vera, Essential thrombocythemia, Primary myelofibrosis, Meta-analysis

\footnotetext{
* Correspondence: jaiberthcardona@gmail.com

${ }^{3}$ School of Microbiology University of Antioquia, School of Medicine,

Cooperativa Universidad de Colombia, Calle 67 Número 53 - 108, Bloque 5,

oficina 103, Medellin, Colombia

Full list of author information is available at the end of the article
}

(c) The Author(s). 2019 Open Access This article is distributed under the terms of the Creative Commons Attribution 4.0 International License (http://creativecommons.org/licenses/by/4.0/), which permits unrestricted use, distribution, and reproduction in any medium, provided you give appropriate credit to the original author(s) and the source, provide a link to the Creative Commons license, and indicate if changes were made. The Creative Commons Public Domain Dedication waiver (http://creativecommons.org/publicdomain/zero/1.0/) applies to the data made available in this article, unless otherwise stated. 


\section{Background}

Myeloproliferative neoplasms (MPN) is a group of eight clinical entities that include those of the $B C R-A B L 1$ negative phenotype, named Philadelphia-negative MPN. These diseases are generated by a clonal disorder in hematopoietic stem cells that leads to an excessive production of mature cells and their accumulation in peripheral blood. The affected lineages of these disorders are erythroid, megakaryocytic and granulocytic, which generate polycythemia vera (PV), essential thrombocythemia (ET) and primary myelofibrosis (PMF). PMF, according to the most recent World Health Organization (WHO) classification of 2016, is subdivided into profibrotic and fibrotic states [1].

From a clinical point of view, patients with MPN are at risk of presenting vascular complications including venous or arterial thrombosis and bleeding. On the other hand, patients with PV and ET can progress to PMF, and all patients with MPN may develop an acute phase of myeloid leukemia [2].

The incidence of PV per 100,000 inhabitants is 0.84 at the global level, and in Europe and North America it has been registered at 0.86 and 0.74 respectively. The data for ET includes an incidence of 1.03 in the world, 1.03 in Europe and 0.96 per 100,000 in North America. For PMF, a global incidence of 0.47 per 100,000 inhabitants has been reported, which does not show marked variation among regions. It is necessary to mention that many studies have been carried out in high-income countries, so it is probable that in middle-income and low-income countries, MPN is misclassified and the incidences may be underestimated [3]. For example, the incidence of MPN in Colombia is not known. However, according to statistics of the National Cancer Institute, of 251 hematological neoplasms diagnosed in 2011, only eight were from the MPN group $[4,5]$.

In 1951, William Dameshek was the first to propose that MPN, mainly chronic myeloid leukemia (CML), PV, ET and PMF, should be categorized as a single group because patients share clinical and laboratory characteristics such as insidious onset, hepatomegaly, splenomegaly and increased cellularity in bone marrow [6]. This led to the diagnosis, risk stratification, clinical characterization and evaluation of the prognosis of patients with MPN being based on hematological analysis of bone marrow and peripheral blood. However, since 2005, with the advent of molecular biology, this panorama changed notably after the discovery of mutations in JAK2 (Janus kinase 2), MPL (trombopoietin receptor) and CALR (calrreticulin) genes identified in PV, ET and PMF. The presence of these markers and the absence of other genetic markers such as $B C R-A B L 1$ have clarified the pathogenesis of these diseases [7], indicating the heterogeneity of the bases of these neoplasms while allowing them to be reunited in the subgroup of $B C R-A B L 1$-negative Chronic MPN as an independent group of chronic myeloid leukemia [8-10].

With this in mind, multiple investigations have been conducted on this group, some of which aimed to determine the frequency and utility of these mutations in the diagnosis, clinical monitoring and prognosis of MPN, demonstrating how their presence, order of acquisition and association with other molecular markers play important roles in the onset of disease [11]. Other studies at the genomic level have focused on determining the frequency and clinical and prognostic implications of JAK2, CALR and MPL mutations called "drivers" $[12,13]$. The prevalence of these markers is variable among the studies; for example, in PV, JAK2 frequencies from 46.7 to $100 \%$ have been reported, and the frequency of CALR in ET also varies, with reports from 12.6 to $50 \%$. Other studies have focused on additional markers related to cellular signaling pathways (tyrosine kinase), oxidative stress, cell cycle (p53) and epigenetic events [14-17]. Likewise, in the evaluation of prognostic factors and complications, different clinical variables have been measured, such as the parameters of blood count, types of treatments used and the patients' age, among others [18, 19].

Currently there are different research approaches to address this group of diseases, which allows the evaluation of a large number of variables to compare various characteristics of patients with PV, ET and PMF. With the diversity of studies, some systematic reviews have focused on molecular issues such as the relationship of a specific mutation with clinical characteristics or prognosis of a single disease $[20,21]$, the comparison of two types of mutations at the prognostic level [22, 23], diagnosis and therapy related to a single mutation [24] and factors associated with the lifestyle, environmental, ethnic and family conditions of patients [25].

Despite this background, no study has characterized the publications made in this subgroup of neoplasms, particularly regarding variables such as years of publication, countries, study populations, detection methods and main study objectives. Additionally, it is necessary to systematize analytical studies comparing different aspects of PV, ET and PMF given that, despite their similarities, there are genetic and clinical markers that differentiate this subgroup, among which is frequency of mutations such as JAK2, MPL and CALR. Additionally, given the large number of reports on these frequencies, it is necessary to obtain a global measure that summarizes the large number of publications and allows the real prevalence of genetic markers in the subgroup of $B C R-A B L$-negative MPN to be known. In the scientific literature, there is no systematic review available of analytical studies about the frequency of these markers. In addition to being major diagnostic criteria, these studies 
provide relevant information on the survival, risk of thrombosis and stratification of patients with favorable or unfavorable prognoses [10].

Therefore, the objective of this review is to characterize the studies of $B C R-A B L 1$-negative chronic myeloproliferative neoplasms and to compare the frequency of $J A K 2$, $M P L$ and CALR mutations in PV, ET and PMF.

\section{Methods}

\section{Type of study}

A systematic review of scientific literature with metaanalysis.

\section{Research protocol according to the PRISMA guide}

Preferred reporting items for systematic reviews and meta-analyses [26]

\section{Identification}

A sensitivity search was carried out (without circumscribing the terms of the thesauri, particularly DeCS and $\mathrm{MeSH}$ ), on three interdisciplinary databases: MedlinePubmed, Scielo, and Science Direct. Additionally, a manual search in Google Scholar was conducted, in which no studies were found in addition to those identified in the aforementioned three databases. These three databases guarantee the completeness of the protocol, given that Pubmed is an interdisciplinary database of the National Library of Medicine of the United States that has accumulated more than 14 million references for biomedical articles since 1950. Scielo is equally interdisciplinary and collects scientific publications from the Spanish and Latin American community, and Science Direct is one of the largest electronic collections in the world.

The identification of the search terms was done by a "pearl harvest", combining the stages of the traditional method and the exhaustive method; that is, to identify relevant articles on the subject, preferably from bibliographic reviews; find the key terms for indexing; search other relevant articles in the database with these terms; and determine other key databases for the search. This process was performed for each database until no new articles were found. The following terms were selected: $B C R-A B L 1$ negative, Chromosome $\mathrm{Ph}$, Philadelphia chromosome, Philadelphia - $\mathrm{Ph}$ - chromosome and Philadelphia translocation [27]. These terms correspond to those frequently used by the experts in the area to describe our study object, which is BCR-ABL1-negative MPN. Likewise, the use of these terms excludes BCRABL1-positive neoplasms from the search, which are mainly chronic myeloid leukemia. With each term, an independent search was made combining all terms with the Boolean operator 'or'; for example, [(BCR-ABL Negative) OR ((Chromosome Ph) OR (Philadelphia chromosome) OR (Philadelphia - $\mathrm{Ph}$ - chromosome) OR
(Philadelphia translocation))]. This step was complemented with a manual search in the references of the selected articles and other manuscripts recommended by experts.

\section{Screening and application of inclusion criteria}

Studies were included that had the search terms in the title, abstract or keywords; lacked time or language limits; were original articles, excluding narrative reviews, short communications, letters to the editor and books; had a main theme of the $B C R-A B L 1$ negative MPN; and described research conducted in humans and in vivo studies. The obtained articles were exported to a common source (EndnoteWeb) and duplicate papers were eliminated.

Some of the syntax used were chromosome ph [Title/ Abstract]; $B C R-A B L$ Negative [Title / Abstract]; TITLEABSTR-KEY ( $B C R A B L$ Negative); (((BCR $A B L$ Negative [Title/Abstract]) OR Chromosome Ph [Title / Abstract]) OR Philadelphia chromosome [Title / Abstract]) OR Philadelphia (Ph) chromosome [Title / Abstract]) OR Philadelphia translocation [Title/Abstract]]; TITLE-ABSTRKEY (BCR ABL Negative) or TITLE-ABSTR-KEY (Chromosome Ph OR Philadelphia chromosome OR Ph chromosome OR Philadelphia translocation); (ti: ((ab: (BCR $A B L$ Negative OR Chromosome Ph OR Philadelphia chromosome OR Ph chromosome OR Philadelphia translocation)))).

This protocol did not present temporal limitations retrospectively, and prospectively, a final update was made in February of 2018. The delimitation of the temporality of the title was based on the decade of the oldest study included in the review.

\section{Selection and application of the exclusion criteria}

In this phase, the following articles were excluded: those with a number of patients less than 10 because these corresponded to case studies or series of cases, manuscripts that were not available in the databases and no response from the authors was received, studies with incomplete data in central variables of the study (such as those that did not specify the number of patients or the type of diagnosis), descriptive studies that evaluated only one disease of the group, experimental or clinical studies and studies that evaluated diagnostic tests.

\section{Inclusion}

The studies that met the above criteria were included in the review. Variables for title, authors, type of study, main subject of the study, journal, year of publication, first author, country of study, number of total patients and by type of disease, demographic and clinical characteristics of the patients, and the main objective of the study were extracted from the manuscripts. With the studies that reported the frequency of mutations, a quantitative synthesis was performed. 
Evaluation of reproducibility and methodological quality The application of the search and selection protocol of the studies was carried out by two researchers independently to guarantee the reproducibility of the review; a priori, it was determined that the discrepancies would be resolved by consensus. The variable extraction phase was carried out independently by two researchers, and a Kappa index of 1.00 was obtained for the variables of country, year, population, and mutation record. Other variables (since their report was text) were made reproducible by a third reviewer. To evaluate the methodological quality, the STROBE (Strengthening the Reporting of Observational studies in Epidemiology) guide was applied, which includes criteria for evaluating the internal and external validity of the included studies [28]. For each article, the compliance with the 22 criteria of the STROBE guide was determined.

\section{Analysis of the information}

The variables were described via frequencies. The frequency of the $J A K 2 V 617 F$ mutation was compared in the study diseases (PV, ET and PML) with a meta-analysis of odds ratios with eight studies that used AS-PCR (Allelespecific polymerase chain reaction) as detection technique because the other techniques were represented by few studies or the methodology of sequencing was not fully explained. For the MPL and CALR mutations, the use of the AS-PCR was less frequent, so a meta-analysis was explored for sequencing and fragment analysis. In all metaanalyses, heterogeneity was assessed with Galbraith, Dersimonian and Laird $(\mathrm{Q}$ statistic with Chi-square distribution) and RI coefficient, the publication bias with Begg statistic and funnel plot, and the sensitivity analysis with an influences graph. The final results of the meta-analysis are presented as forest plots. Subsequently, a meta-regression was performed by diagnostic criteria for $J A K 2$, separating articles that used WHO criteria from 2001 and 2008.

\section{Results}

In the application of the search and selection protocol, 11,596 studies were obtained without the application of limits or filters to the databases. This number was reduced to 1228 that included the terms in title or abstract, to these were added 7 from the manual search. After the application of the inclusion and exclusion criteria, a qualitative synthesis of the information of 52 articles and a quantitative synthesis (meta-analysis) of 18 studies that compared the frequency of the JAK2V617F, $M P L$ and $C A L R$ mutation by type of disease were performed (Fig. 1).

The selected studies were published in 20 different countries. The United States, China, and Brazil had the highest number of studies with 10, nine and six, respectively. The other countries had between one and three publications (Fig. 2).

An evaluation of the methodological quality of the included studies showed that the percentage of compliance was greater than $70 \%$ of the criteria of the STROBE guide. The criteria that had the lowest compliance percentage were the explanation of the sample size and the discussion of the possibility of generalizing the results obtained (Fig. 3).

Studies published between 2003 and 2018 were identified. The highest proportion were in 2016, with $19.2 \%$ ( $n=10$ studies), and 2015, with $17.3 \%$ ( $n=9$ studies), whereas between 2003 and 2014, the frequency of studies ranged between one and four per year. A total of 27 , 078 study subjects were included, of which $12.9 \%(n=$ 3488 ) corresponded to patients with PV, 19.6\% ( $n=$ $5300)$ with ET, $7.2 \%(n=1954)$ with PMF and $60.3 \%$ to healthy controls $(n=1070)$ and people with other diseases $(n=15,266)$ (Table 1$)$.

The results of the studies showed a high degree of heterogeneity. The first group included studies that genetically characterized MPN from different aspects, among which the detection of methylations [17] and epigenetic alterations [31], the search of structural rearrangements in JAK2 [33], comparative genomics for the diagnosis [37], the identification of new genetic markers [14], and mutations associated with pathogenesis [60] or mutations in $C A L R$ and $M P L$ in negative $J A K 2$ patients $[41,70]$ all stood out. Another group of studies focused on clinical aspects of MPN, describing hemorrhagic complications [19], clinical manifestations [57], symptomatology [63] or the relationship of hematological characteristics with clinical complications [18]. Finally, a third subgroup included publications related to the characterization of cellular and metabolic processes, such as the measurement of the expression of the protein $\mathrm{B}$ catenin in $B C R-A B L$-negative MPN [58], the relationship of immune modulators with MPN [65], polymorphisms in oxidative stress genes [15] or the measurement of serum levels of proteins related to angiogenesis in MPN [71].

Of the included studies, twenty analyzed the frequency of the JAK2V617F mutation in PV, ET and PMF. These show heterogeneous results in the diagnostic techniques and the proportion of patients with the mutation. The proportion of patients with the mutation ranging from 46.7 to $100 \%$ in patients with PV, from 31.3 to $72.1 \%$ in patients with ET, and from 25.0 to $85.7 \%$ in those with PMF (Table 2). Of these studies, eight used the AS-PCR test to detect the mutation. Based on this information, three meta-analyses were performed to compare the frequency of the mutation among the three diseases.

When comparing the odds ratios for the frequency of mutations in patients with PV compared to patients with ET, homogeneity was found between the studies (Galbraith 


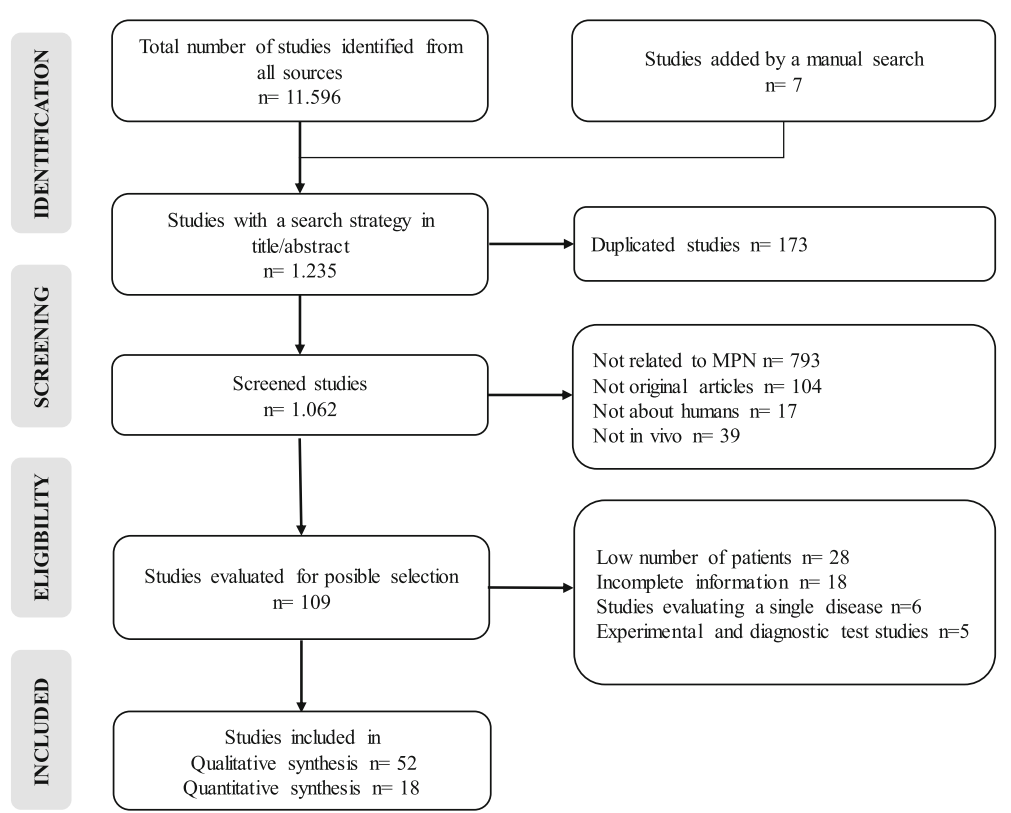

Fig. 1 Flow-gram of search and selection of articles

chart). No publication bias was presented according to a funnel plot, and an impact graph confirmed the relevance of a combined measure insofar as the exclusion of each study in successive stages did not generate changes in the summary measure. The accumulated meta-analysis corroborated that the conclusion derived from the summary measure did not change with an increase of sample size or the inclusion of additional patients (Fig. 4).

Finally, the odds ratio for the comparison of the frequency of mutations in patients with PV versus subjects with ET, based on a fixed-effect meta-analysis, was 3.0 (95\% CI $=2.0-4.4)$, for the comparison between PV and PMF it was $4.0(95 \% \mathrm{CI}=2.3-7.0)$, whereas in the comparison between ET and PMF an OR of 1.3 was obtained $(95 \% \mathrm{CI}=0.8-2,2)$. This indicates that the risk of presenting this mutation in patients with $\mathrm{PV}$ is 3.0 times more likely to be found in ET and 4.0 times more frequently observed in people with PMF, whereas the probability of finding the mutation in ET and PMF is statistically similar (Fig. 5).

The MPL mutation was analyzed in 14 studies, and presented with the frequencies $0 \%$ in PV, from 0.9 to $12.5 \%$ in ET, and from 0 to $17.1 \%$ in PMF. The CALR mutation was reported in 13 studies, with a frequency of $0.0 \%$ in PV. In ET it ranged from 12.6 to $50 \%$ and in PMF from 10 to $100 \%$ (Table 3).

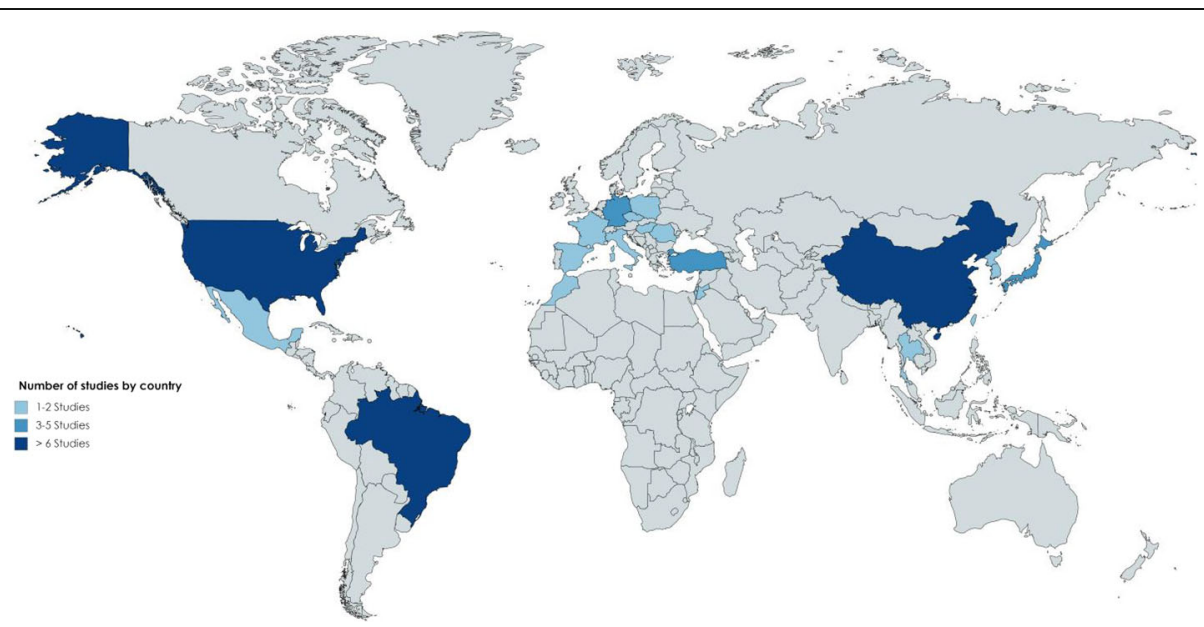

Fig. 2 Absolute frequency of studies by country 
STROBE item

Title and abstract

Background - Rationale

Objectives

Study design

Setting

Participants: Eligibility criteria

Variables

Data sources - Measurement

Bias

Study size

Statistical methods

Results of participants

Descriptive data

Outcome data

Main results

Other analyses

Discussion of key results

Limitations

Interpretation

Generalizability

Funding
Studies that accomplish the item (\%)

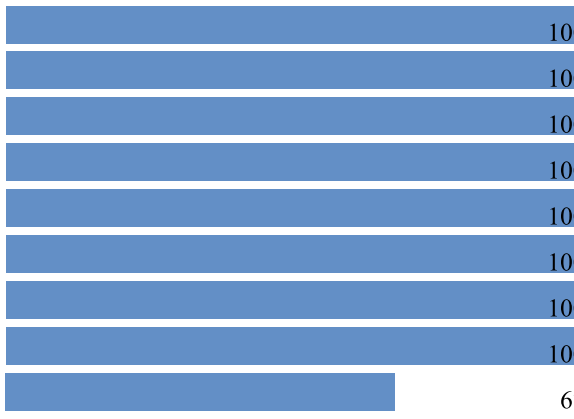

67

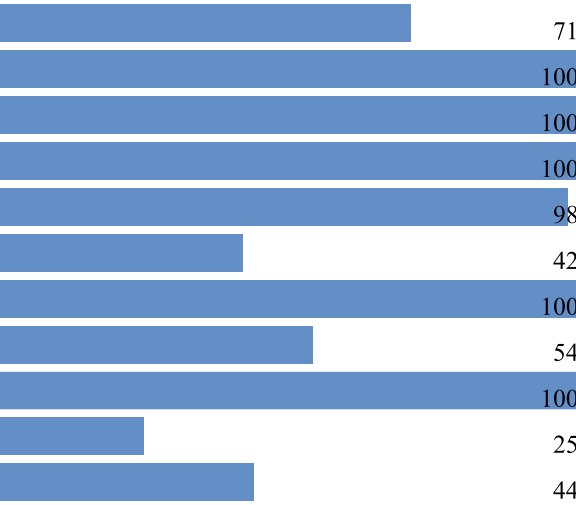

Fig. 3 Evaluation of methodological quality

In $M P L$ and $C A L R$, only 3 studies used AS-PCR, so only one combined measure was estimated for sequencing and fragment analysis, without finding heterogeneity between the studies (Galbraith). No publication bias was found, and the sensitivity analysis demonstrated strength in the combined measure.

Based on a meta-analysis under a fixed-effect model, the comparison of the frequency of MPL in ET and PMF showed an OR of 0.3 (95\% CI $=0.2-0.6)$, and for CALR between ET and PMF, the OR was $1.1(95 \% \mathrm{CI}=0.8-1.5)$ . These findings demonstrate that the probability of presenting the MPL mutation in PMF is approximately three times greater than for ET, whereas the frequency of CALR is statistically similar in both diseases (Fig. 5).

Five studies reported the frequency of the JAK2 mutation with the diagnostic criteria recommended by the WHO 2001 [34-36, 38, 55]. In their combined measurement, an OR of 3.5 was obtained $(95 \% \mathrm{CI}=1.6-7.7)$. Eight studies used the WHO 2008 criteria [41, 48-51, $54,62,66]$, for which an OR of $4.7(95 \% \mathrm{CI}=3.1-7.5)$ was found. Three studies used WHO 2008 criteria and AS-PCR, and their combined measurement was an OR of $3.8(95 \% \mathrm{CI}=1.6-8.3)$. These analyzes by subgroups showed that JAK2 is more frequent in PV than in ET, regardless of the technique or diagnostic criterion used. Although the comparison of the intervals did not show significant differences, greater strength of association was observed when applying the WHO 2008 criteria.

For the frequency of the CALR and MPL mutations, it was not possible to perform a meta-regression according to the diagnostic criteria, because the subgroups only contained two to three studies.

\section{Discussion}

In this review, 52 studies comparing different variables in 3488 people with PV, 5300 with ET, and 1954 with PMF were systematized, as were 1070 controls, with a majority of the studies being from the United States, China, and Brazil. A total of 20 studies analyzed the frequency of the JAK2V617F mutation in the three diseases, and meta-analysis showed that the risk of presenting this mutation in PV is much higher than for ET and PMF. Fourteen studies analyzed the frequency of the MPL mutation, and meta-analysis showed that the probability of having the mutation is higher in PMF than in ET. The frequency of CALR was reported in 13 studies, and no significant differences were found between the two diseases. These findings demonstrate the high external validity of this review while highlighting following factors: the small number of analytical investigations that have been carried out, a high diversity in the comparison of clinical and genetic parameters in Philadelphia-negative 
Table 1 Description of the studies included in the review according to the year of publication and the number of subjects studied

\begin{tabular}{|c|c|c|c|c|c|c|}
\hline Author & Year & Country & N PV & N ET & N PMF & $N$ others \\
\hline Aviram A [17] & 2003 & Israel & 31 & 56 & 10 & 0 \\
\hline Hsu H [29] & 2004 & Taiwan & 16 & 30 & 0 & $17^{\mathrm{a}} 51^{\mathrm{b}}$ \\
\hline Jelinek J [30] & 2005 & U.S.A. & 29 & 10 & 19 & $316^{a}$ \\
\hline Jost E [31] & 2007 & Germany & 9 & 7 & 0 & $23^{a}$ \\
\hline Zhang S [32] & 2007 & China & 23 & 40 & 8 & $23^{\mathrm{a}}$ \\
\hline Najfeld V [33] & 2007 & U.S.A. & 18 & 0 & 6 & $15^{\mathrm{a}}$ \\
\hline Suzuki R [34] & 2007 & Japan & 15 & 21 & 5 & $8^{\mathrm{a}}$ \\
\hline Xu W [35] & 2008 & China & 32 & 102 & 13 & $43^{a} 50^{b}$ \\
\hline Lucia E [36] & 2008 & Italy & 108 & 74 & 26 & $25^{a} 50^{b}$ \\
\hline Tefferi A [37] & 2009 & U.S.A. & 26 & 13 & 32 & 0 \\
\hline Tefferi A [38] & 2009 & U.S.A. & 89 & 57 & 60 & $33^{\mathrm{a}}$ \\
\hline Aranaz P [14] & 2010 & Spain & 4 & 15 & 4 & $21^{a}$ \\
\hline Tripodi J [39] & 2010 & U.S.A. & 47 & 21 & 52 & $26^{a}$ \\
\hline Chen X [40] & 2011 & China & 15 & 70 & 18 & 0 \\
\hline Toyama K [41] & 2011 & Japan & 25 & 82 & 8 & 0 \\
\hline Benmoussa A [42] & 2011 & Morocco & 19 & 8 & 12 & $31^{\mathrm{a}}$ \\
\hline da Silva R [43] & 2012 & Brazil & 52 & 81 & 11 & 0 \\
\hline Zhang X [44] & 2012 & China & 51 & 66 & 17 & 0 \\
\hline Ho C [45] & 2012 & Taiwan & 21 & 32 & 5 & $20^{a}$ \\
\hline Schnittger S [46] & 2012 & Germany & 736 & 615 & 230 & $13961^{\mathrm{a}}$ \\
\hline Pagliarini S [47] & 2013 & Brazil & 17 & 22 & 12 & $5^{\mathrm{a}} 90^{\mathrm{b}}$ \\
\hline Patriarca A [48] & 2013 & Italy & 26 & 55 & 9 & $8^{a}$ \\
\hline Kim H [49] & 2013 & Korea & 26 & 42 & 7 & $3^{\mathrm{a}}$ \\
\hline Wu Z [50] & 2014 & China & 80 & 80 & 50 & 0 \\
\hline Kissova J [18] & 2014 & Czech Republic & 41 & 105 & 36 & 0 \\
\hline Payzin K [51] & 2014 & Turkey & 81 & 129 & 22 & 0 \\
\hline Macedo L [52] & 2015 & Brazil & 38 & 42 & 33 & $30^{\mathrm{a}} 150^{\mathrm{b}}$ \\
\hline Ouyang Y [53] & 2015 & China & 48 & 171 & 27 & $180^{\mathrm{a}} 20^{\mathrm{b}}$ \\
\hline Kander E [19] & 2015 & U.S.A. & 118 & 144 & 63 & $26^{a}$ \\
\hline Mahjoub S [54] & 2015 & France & 22 & 17 & 17 & 0 \\
\hline Jaradat S [55] & 2015 & Jordan & 27 & 16 & 14 & 0 \\
\hline Labastida N [56] & 2015 & Mexico & 14 & 8 & 4 & 0 \\
\hline Duangnapasatit B [57] & 2015 & Thailand & 68 & 83 & 6 & 0 \\
\hline Geduk A [58] & 2015 & Turkey & 7 & 43 & 16 & $30^{\mathrm{b}}$ \\
\hline Lin $Y$ [59] & 2015 & China & 234 & 428 & 187 & $80^{a}$ \\
\hline Berzoti M [60] & 2016 & Brazil & 14 & 24 & 9 & $60^{\mathrm{a}} 35^{\mathrm{b}}$ \\
\hline Macedo L [61] & 2016 & Brazil & 33 & 35 & 22 & $33^{a} 123^{b}$ \\
\hline Didone A [62] & 2016 & Brazil & 20 & 28 & 20 & $68^{a}$ \\
\hline Xu J [63] & 2016 & China & 171 & 269 & 188 & 0 \\
\hline McFarland D [64] & 2016 & U.S.A. & 34 & 31 & 31 & $21^{a}$ \\
\hline Wang J [65] & 2016 & U.S.A. & 17 & 11 & 23 & $42^{\mathrm{a}} 43^{\mathrm{b}}$ \\
\hline Gardner J [66] & 2016 & U.S.A. & 7 & 3 & 3 & $34^{a}$ \\
\hline Trifa A [15] & 2016 & Romania & 140 & 140 & 48 & $363^{b}$ \\
\hline Delic S [67] & 2016 & Germany & 30 & 40 & 30 & 0 \\
\hline
\end{tabular}


Table 1 Description of the studies included in the review according to the year of publication and the number of subjects studied (Continued)

\begin{tabular}{|c|c|c|c|c|c|c|}
\hline Author & Year & Country & N PV & N ET & N PMF & $\mathrm{N}$ others \\
\hline Orvain C [68] & 2016 & France & 42 & 93 & 35 & $86^{a} 26^{b}$ \\
\hline Goel S [69] & 2017 & U.S.A. & 51 & 19 & 73 & 0 \\
\hline Smaili W [70] & 2017 & Morocco & 0 & 22 & 11 & 0 \\
\hline Gadomska G [71] & 2017 & Poland & 19 & 46 & 7 & $39^{b}$ \\
\hline Yildiz I [72] & 2017 & Turkey & 23 & 68 & 9 & 0 \\
\hline Li M [73] & 2017 & China & 508 & 1049 & 91 & 0 \\
\hline Misawa K [74] & 2018 & Japan & 166 & 212 & 88 & $27^{\mathrm{a}}$ \\
\hline Gángó A [75] & 2018 & Hungary & 0 & 425 & 227 & 0 \\
\hline Total & & & 3488 & 5300 & 1954 & 16,336 \\
\hline
\end{tabular}

${ }^{\mathrm{a}}$ Other diseases (hematológicas) ${ }^{\mathrm{b}}$ Healthy controls

MPN, and that few studies of the frequency of mutations exist. These together show a great potential for the orientation and consolidation of research in this group of neoplasms.

It is evident from the publications included in this systematic review that the largest proportion of studies come from the United States, China, and Brazil, which indicates the increasing interest these countries have in studying MPN, as is the case with European countries also. In general, most of the publications come from medium- and high-income countries, which could imply a relationship between the research development in this area and the access or availability of reference centers for the diagnosis and treatment of this type of disease. In the United States, for example, there are the American Society of Hematology, the Leukemia and Lymphoma Society, and the Research Foundation in Myeloproliferative Neoplasms; in Brazil the Brazilian Association of Hematology, Hemotherapy and Cell Therapy; in Europe the European

Table 2 Absolute and relative frequencies of the JAK2V617F mutation

\begin{tabular}{|c|c|c|c|c|c|}
\hline Author & Diagnostic criteria & Technique & PV \% (n) & ET \% (n) & PMF \% (n) \\
\hline Zhang SJ [32] & No data & AS-PCR & $69.6(16)$ & $45.0(18)$ & $37.5(3)$ \\
\hline Suzuki R [34] & WHO 2001 & Sequencing & $46.7(7)$ & $47.6(10)$ & $80.0(4)$ \\
\hline Xu W [35] & WHO 2001 & AS-PCR & $62.5(20)$ & $42.2(43)$ & $38.5(5)$ \\
\hline Lucia E [36] & WHO 2001 & AS-PCR & $90.2(74)$ & $72.1(31)$ & $63.2(12)$ \\
\hline Tefferi A [38] & WHO 2001 & RT-PCR & $89.9(80)$ & $45.6(26)$ & $55.0(33)$ \\
\hline Toyama K [41] & WHO 2008 & AS-PCR & $88.0(22)$ & $68.3(56)$ & $75.0(6)$ \\
\hline Benmoussa A [42] & No data & AS-PCR & $89.5(17)$ & $62.5(5)$ & $33.3(4)$ \\
\hline Zhang X [44] & No data & AS-PCR & $84.3(43)$ & $69.7(46)$ & $52.9(9)$ \\
\hline Ho C [45] & No data & HRM & $76.2(16)$ & $46.9(15)$ & $80.0(4)$ \\
\hline da Silva R [43] & No data & PCR-RFLP & $88.5(46)$ & $48.1(39)$ & $72.7(8)$ \\
\hline Kim H [49] & WHO 2008 & AS-PCR & $88.5(23)$ & $57.1(24)$ & $85.7(6)$ \\
\hline Patriarca A [48] & WHO 2008 & Real-time PCR & $100(26)$ & $63.6(35)$ & $66.7(6)$ \\
\hline Wu Z [50] & WHO 2008 & HRM Sequencing & $82.5(66)$ & $56.3(45)$ & $58.0(29)$ \\
\hline Payzin K [51] & WHO 2008 & Real-time PCR & $95.1(77)$ & $68.2(88)$ & $77.3(17)$ \\
\hline Labastida N [56] & Conventional & ARMS & $62.5(5)$ & $35.7(5)$ & $25.0(1)$ \\
\hline Mahjoub S [54] & WHO 2008 & AS-PCR & $72.7(16)$ & $47.1(8)$ & $66.7(2)$ \\
\hline Jaradat S [55] & WHO 2001 & Sequencing & $70.4(19)$ & $31.3(5)$ & $14.3(2)$ \\
\hline Gardner J [66] & WHO 2008 & Fragment Analysis PCR & $100.0(7)$ & $66.7(2)$ & $33.3(1)$ \\
\hline Didone A [62] & WHO 2008 & PCR-RFLP & $95.0(19)$ & $71.4(20)$ & $40.0(8)$ \\
\hline Yildiz I [72] & $\mathrm{WHO}$ & Sequencing & $73.9(17)$ & $61.8(42)$ & $55.6(5)$ \\
\hline
\end{tabular}




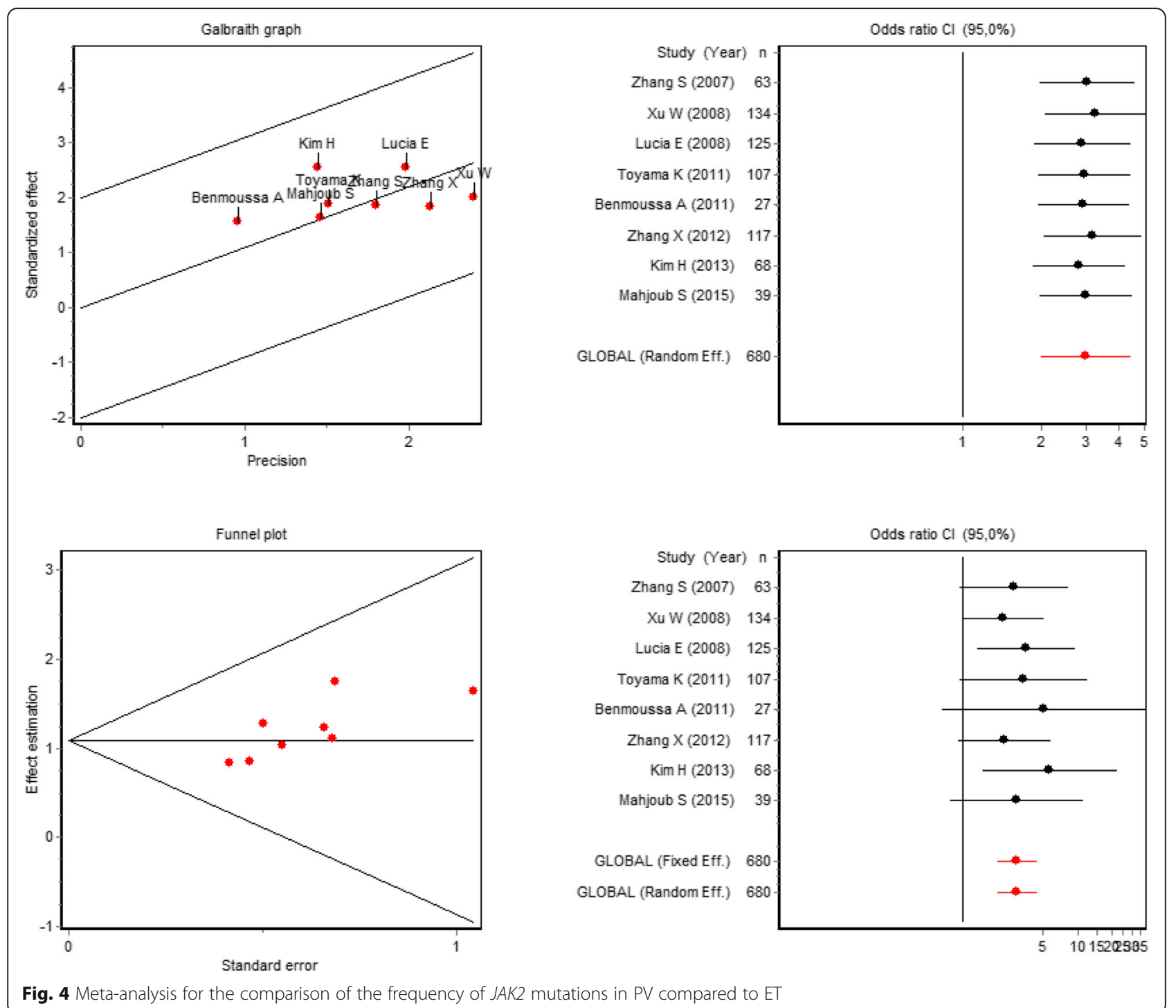

Association of Hematology and the Spanish Society of Hematology and Hemotherapy.

This contrasts with other places with a low frequency of studies. In Colombia, for example, where the incidence of this group of diseases has not been determined, only a few studies describing the clinical characteristics of patients with MPN have been conducted, one of which is a publication by the Colombian Association of Hematology and Oncology. This indicates the myriad obstacles to carrying out this type of research, such as the deficit of professionals in hematopathology and the lack of access to specialized studies for diagnosis [5].

In this systematic review, ET was the most frequently reported disease, with a total of 5300 cases corresponding to $49.34 \%$ of all patients with MPN, followed by PV with $32.47 \%$ and PMF with 18,19\%. This distribution correlates with the incidents reported worldwide for this group of neoplasms. For example, a recent study conducted in
Korea, with 4342 patients showed higher incidences for ET, followed by PV and PMF [76]. A meta-analysis carried out on American and European studies mainly had the same distribution of the three diagnoses [3]. In Norway, a study conducted in 2017 with 2453 people showed that TE may have slightly higher prevalence than PV, and of the three, PMF had the lowest incidence [77].

On the other hand, there was high heterogeneity in the purposes of the included studies. One of the topics evaluated was epigenetic alterations. Studies on this topic have been very relevant to the explanation of pathogenesis and the evaluation of the influence of nongenetic factors on the development of MPN [31]. Currently, epigenetics is an important topic of study in the field of pharmacogenomics in many types of diseases, and through it we try to identify therapeutic targets for conventional therapy that are specific to each patient to encourage the application of personalized medicine [78]. 


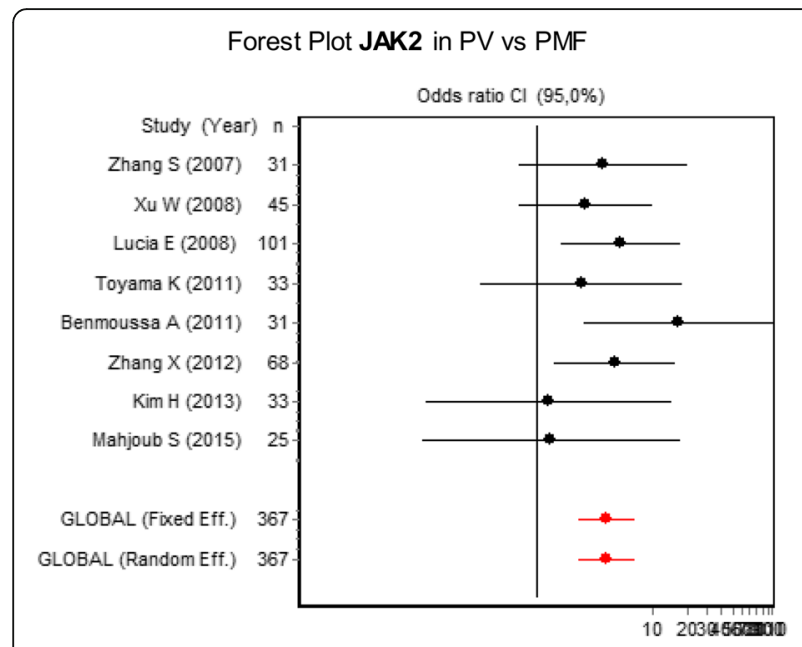

Forest Plot JAK2 TE vs PMF

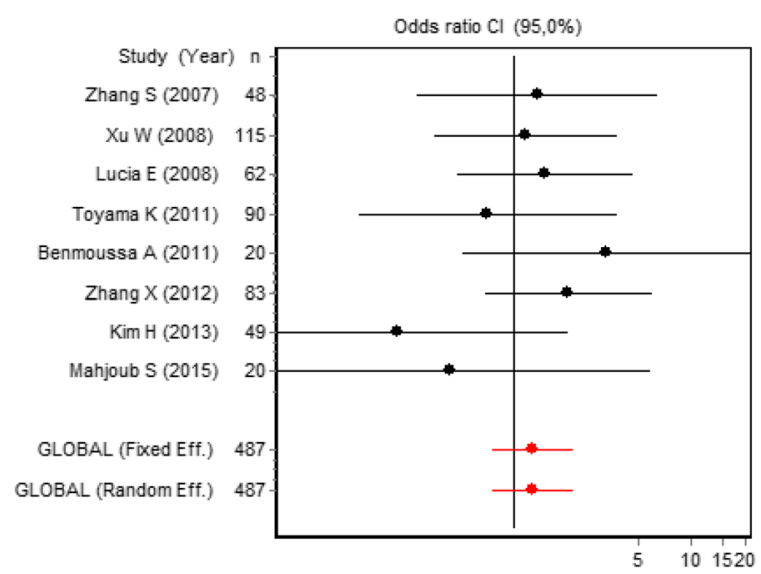

Forest Plot MPL TE vs PMF

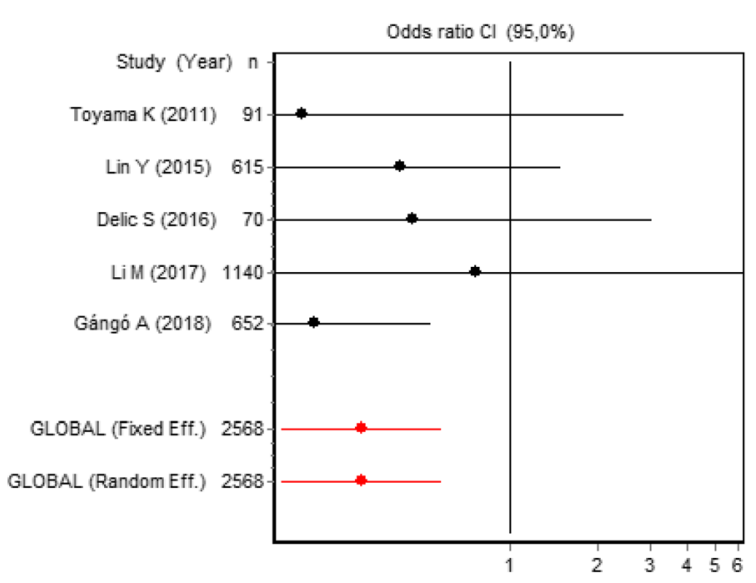

Forest Plot CALR TE vs PMF

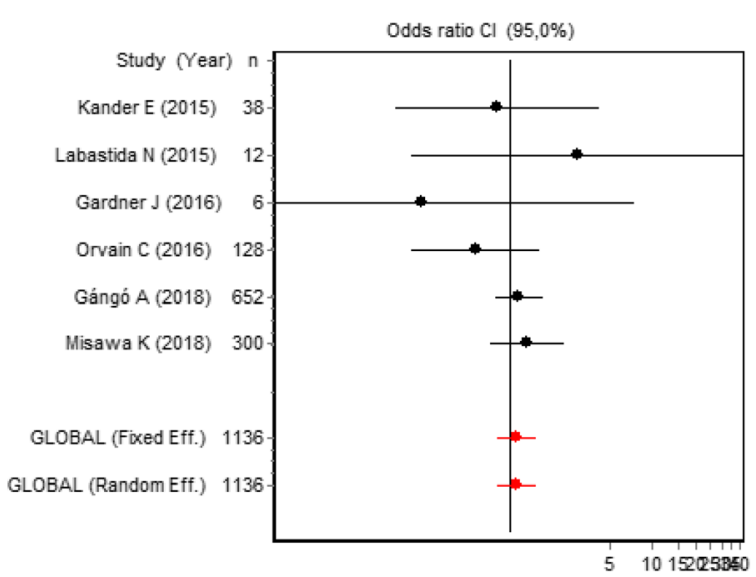

Fig. 5 Forest plot for the comparison of the frequency of JAK2 mutations between PV vs PMF and ET vs PMF, comparison of MPL mutations in ET vs PMF and of CALR mutations in ET vs PMF

In addition, studies that have focused on the hematological and clinical characteristics of the MPN have been very valuable because they mark the initial guidelines for the diagnosis of suspicious patients and have defined medical and therapeutic behaviors.

Despite the diversity of publications in the present review, the interest of some researchers in the exploration of MPN at the genetic level was clear, both via the search for new mutations and by determining the frequency and implications at the level of diagnosis, prognosis and pathogenesis of mutations already described. This interest can be attributed to the impact that the different genetic markers have had on the understanding of this group of diseases, their reclassification by being able to separate them from CML as an independent group [79], the therapeutic orientation to more specific and less invasive targets [80], and the improved management of the progression of the disease, among other factors.
The driver mutations, which include alterations in the JAK2, MPL and CALR genes, constitute a subject of great interest in this area. Their importance lies in the high frequency reported in ET, PV, and PMF, as well as their specificity for diagnosis. It is evident from this review that the main interest has been the frequency and clinical correlation of these three mutations. However, several studies evaluated other mutations in the TET2 gene related to the development of blast crisis and acute myeloid leukemia, which is currently an interesting line of research [81].

In addition to the genetic screening of these three driver mutations, several authors strongly recommend a search for a $B C R-A B L 1$ fusion gene as an initial step for the diagnosis of MPN insofar as it allows the exclusion of chronic myeloid leukemia, which is the most frequent entity of this group of neoplasms. The development of molecular tests in this area of hematology has allowed the implementation of diagnostic algorithms that lead to 
Table 3 Absolute and relative frequencies of the MPL and CALR mutations

\begin{tabular}{|c|c|c|c|c|c|c|c|c|}
\hline \multirow[b]{2}{*}{ Author } & \multicolumn{4}{|l|}{ MPL Mutation } & \multicolumn{4}{|l|}{ CALR Mutation } \\
\hline & Technique & PV \% (n) & ET \% (n) & PMF \% (n) & Technique & PV \% (n) & ET \% (n) & PMF \% (n) \\
\hline $\mathrm{Xu}[35]$ & AS-PCR & $0(0)$ & $1.0(1)$ & $0(0)$ & ND & ND & ND & ND \\
\hline Chen [40] & AS-PCR & $0(0)$ & $1,4(1)$ & $5,6(1)$ & ND & ND & ND & ND \\
\hline Toyama [41] & Sequencing & $0(0)$ & $2,4(2)$ & $0(0)$ & ND & ND & ND & ND \\
\hline $\mathrm{Wu}[49]$ & Real-time PCR & $0(0)$ & $5,0(4)$ & $6,0(3)$ & Sequencing & $0(0)$ & $25,0(2) 0)$ & $20,0(16)$ \\
\hline Labastida [55] & ARMS & $0(0)$ & $12,5(1)$ & $0(0)$ & Fragment analysis & $0(0)$ & $50,0(4)$ & $25,0(1)$ \\
\hline Trifa [15] & SNP & $0(0)$ & $1,4(2)$ & $4,2(2)$ & SNP & $0(0)$ & $29,3(41)$ & $25,0(12)$ \\
\hline Gadomska [70] & ND & ND & $5,3(1)$ & $0(0)$ & ND & ND & $31,6(6)$ & $100(2)$ \\
\hline Li [72] & Sequencing & ND & $0,9(9)$ & $1,1(1)$ & Sequencing & ND & $12,6(132)$ & $12,1(11)$ \\
\hline Schnittger S [46] & PCR & ND & $7,1(44)$ & $13,2(17)$ & ND & ND & ND & ND \\
\hline Misawa [73] & AS-PCR & $0(0)$ & $4,7(10)$ & $1,1(1)$ & Fragment analysis & $0(0)$ & $26,9(57)$ & $21,6(19)$ \\
\hline Gángó [74] & Sequencing & ND & $1,6(7)$ & $7,1(16)$ & Fragment analysis & ND & $24,5(104)$ & $21,6(49)$ \\
\hline Lin [58] & Sequencing & $0(0)$ & $1,2(5)$ & $2,7(5)$ & Sequencing & $0(0)$ & $22,7(97)$ & $17,6(33)$ \\
\hline Delic [66] & Sequencing & $0(0)$ & $5,0(2)$ & $10(3)$ & Sequencing & $0(0)$ & $25,0(10)$ & $10,0(3)$ \\
\hline Orvain [67] & Real-time PCR & ND & $2,2(2)$ & $17,1(6)$ & Fragment analysis & ND & $12,9(12)$ & $20.0(7)$ \\
\hline Kander [19] & ND & ND & ND & ND & Fragment analysis & ND & $33,3(10)$ & $37,5(3)$ \\
\hline Gardner [65] & ND & ND & ND & ND & Fragment analysis & $0(0)$ & $33,3(1)$ & $66,7(2)$ \\
\hline Smaili [69] & ND & ND & ND & ND & Sequencing & ND & $50,0(11)$ & $36,4(4)$ \\
\hline
\end{tabular}

$A S-P C R$ Allele-specific polymerase chain reaction, $P C R$ polymerase chain reaction, ARMS Amplification-refractory mutation system, SNP single-nucleotide polymorphism, ND No Data

an accurate diagnosis in a logical order according to the frequency of each neoplasm [82].

The most frequently studied mutations were JAK2V617F, $M P L$ and CALR. JAK2V617F presents more frequently in $\mathrm{PV}$, whereas in $\mathrm{ET}$ and PMF, in the absence of $J A K 2$, different mutations in the CALR and MPL genes are present in a large proportion of patients. These mutations are responsible for both the onset and the pathogenesis of the disease, and alter important cellular signaling pathways [83]. The $J A K 2$ gene codes for the Janus kinase 2 protein, which participates in the JAK-STAT signaling pathway that is important in cellular processes such as proliferation and differentiation. The main alteration is a change of amino acids that generates the JAK2V617F mutation. However, insertions and deletions in exon 12 result in other mutations in the JAK2 gene that are less frequent [84, 85]. The CALR gene codes for the calreticulin protein, which functions in calcium homeostasis and as a chaperone [9]. The mechanism by which mutations in CALR neoplasically transform cells is not completely clear, but it has been described as being dependent on interaction with receptors such as MPL [78]. The main mutation described for the gene of the trompopoietin receptor is MPLW515L, which causes an amino acid substitution in the protein and results in constitutive activation of the JAK-STAT signaling pathway [8].

The meta-analysis showed that the probability of presenting JAK2V617F mutation in patients with $\mathrm{PV}$ is 3.0 times higher than for ET and 4.0 times higher than PMF.
The probability of having the MPL mutation is 3.0 times higher in patients with PMF compared with ET, and there are no significant differences in the probability of having CALR between the two entities. In addition, in the analysis of subgroups for the frequency of the JAK2V617F mutation carried out in our study, a greater association was found in the frequency of the mutation with the WHO 2008 diagnostic criteria, which can be attributed to the greater specificity for the diagnosis of these neoplasms defined in this year [79].

These results confirm that the JAK2V617F mutation can constitute an important marker for the diagnosis of PV. The presence of this mutation has important clinical and prognostic implications, given that homozygous patients present a higher risk of splenomegaly and cardiovascular events. Specifically, in patients with PV, this marker is associated with higher levels of hemoglobin and neutrophil counts and fibrotic transformation [86].

The results of our meta-analysis of MPL revealed an increased risk of having the mutation in PMF with respect to ET. For some authors, this finding was associated with the prognosis of patients with ET, as they show greater progression to fibrosis, lower levels of hemoglobin and greater age. A similar pattern was seen for other authors in cases of ET with mutations in MPL. These might represent prefibrotic states of PMF [87-90]; however, studies on this topic are few and it is not possible to establish a relationship between the mutation and the prognosis. 
On the other hand, the detection of mutations in the $J A K 2$ gene and in other genes is greatly influenced by the sensitivity and specificity of the detection technique used, as well as by the type and management of the sample. In this regard, all these details should be taken into account as recommended in the guide for the molecular diagnosis of myeloproliferative neoplasms in the United Kingdom in 2012 [82].

These findings, in conjunction with WHO recommendations, show that a diagnosis of MPN should not be isolated from genetic markers, and therefore, both the clinical and hematological characteristics and the presence or absence of these mutations should be taken into account. In addition, the findings show that mutations in exon 12 of the $J A K 2$ gene should also be considered before discarding PV [1].

Among the limitations of this study is the impossibility of explaining the sources of heterogeneity in the metaanalyses, as the individual studies were not exhaustive in their reporting of results by subgroups. The great advantage of this work is that it allowed the characterization of publications on MPN by general topics, such as years of publication, countries, and topics of interest, among others. Additionally, through this study, the current panorama of analytical investigations in this group of diseases was determined.

\section{Conclusion}

The largest proportion of studies come from countries with high economic and research development and have been published mainly in the last 3 years. Despite the heterogeneity found in the purposes of the studies, there was a greater interest in genetic approaches, mainly concerning the JAK2V617F, MPL and CALR mutations. Given their specificity and high reported frequencies in this group of neoplasms, the diagnosis of these entities should not be made only by clinical and hematological characteristics alone but also by the genetic screening of patients. Finally, the presence of the driver mutations can be closely related to clinical and prognostic factors in this group of neoplasms; however, it is necessary to develop a greater number of studies on this topic, as well as the systematization of these studies to determine the real association of these frequencies with other aspects of the disease.

\section{Abbreviations}

CALR: Calrreticulin; CML: Chronic Myeloid Leukemia; ET: Essential Thrombocythemia; JAK2: Janus kinase 2; MPL: Trombopoietin receptor; MPN: MyeloProliferative Neoplasms; PMF: Primary MyeloFibrosis; PRISMA: Preferred Reporting Items for Systematic Reviews and Meta-analyses; PV: Polycythemia Vera; WHO: World Health Organization

\section{Authors' contributions}

$\mathrm{MMO}$ and JACA made important contributions in the study design, collection of information and writing of the article, JACA carried out the statistical analyzes of the entire manuscript. MMO, PAAT and JACA participated in the supervision and review of the article, MMO, PAAT and JACA participated in conception of the work and to ensure the accuracy or integrity of any part of the work. All authors have read and approved the manuscript.

\section{Funding}

In-kind resources from the University of Antioquia and Cooperative University of Colombia were used to carry out the study. The funding universities had no influence on the design of the study and collection, analysis, and interpretation of data and in writing the manuscript.

Availability of data and materials

All the data are available in the article.

Ethics approval and consent to participate

Not applicable.

\section{Consent for publication}

Not applicable.

\section{Competing interests}

The authors declare that they have no competing interests.

\section{Author details}

${ }^{1}$ Molecular Hematopathology Research Group, School of Microbiology,University of Antioquia, Laboratorio Médico de referencia, Medellin, Colombia. ${ }^{2}$ Molecular Hematopathology Research Group, School of Microbiology, University of Antioquia, Medellin, Colombia. ${ }^{3}$ School of Microbiology University of Antioquia, School of Medicine, Cooperativa Universidad de Colombia, Calle 67 Número 53 - 108, Bloque 5, oficina 103, Medellin, Colombia.

Received: 25 July 2018 Accepted: 28 May 2019

Published online: 17 June 2019

\section{References}

1. Arber DA, Orazi A, Hasserjian R, Borowitz MJ, Le Beau MM, Bloomfield CD, et al. The 2016 revision to the World Health Organization classi fi cation of myeloid neoplasms and acute leukemia. Blood. 2016;127(20):2391-406.

2. Rumi E, Cazzola M. Diagnosis, risk stratification, and response evaluation in classical myeloproliferative neoplasms. Blood. 2016; blood-2016-10-695957. Available from: http://www.bloodjournal.org/lookup/doi/10.1182/blood2016-10-695957. Accessed June 2018.

3. Titmarsh GJ, Duncombe AS, Mcmullin MF, O'Rorke M, Mesa R, De Vocht F, et al. How common are myeloproliferative neoplasms? A systematic review and meta-analysis. Am J Hematol. 2014;89(6):581-7.

4. Ferlay J, Soerjomataram I, Dikshit R, Eser S, Mathers C, Rebelo M, et al. Cancer incidence and mortality worldwide: sources, methods and major patterns in GLOBOCAN 2012. Int J Cancer. 2015;136(5):E359-86. https://doi. org/10.1002/ijc.29210.

5. S MH, C CP, C BD, S D, Q M, L JF, et al. Descripción de las características clínicas de las neoplasias mieloproliferativas crónicas ( NMPC) Description of the clinical characteristics of chronic myeloproliferative neoplasms ( MPNs) First report of the colombian registry of MPNs. 2017;35-41.

6. Dameshek W. Some speculations on the myeloproliferative syndromes. Blood. 1951;6(4):372-5 Blood. United States; 2016 Feb;127(6):663.

7. James C, Ugo V, Le Couédic J-P, Staerk J, Delhommeau F, Lacout C, et al. A unique clonal JAK2 mutation leading to constitutive signalling causes polycythaemia vera. Nature. 2005;434(7037):1144-8 Available from: http:// www.ncbi.nlm.nih.gov/pubmed/15793561.

8. Pikman Y, Lee BH, Mercher T, McDowell E, Ebert BL, Gozo M, et al. MPLW515L is a novel somatic activating mutation in myelofibrosis with myeloid metaplasia. PLoS Med. 2006;3(7):1140-51.

9. Nangalia J, Massie CEE, Baxter EJ, Nice FLL, Gundem G, Wedge DCC, et al. Somatic CALR mutations in myeloproliferative neoplasms with nonmutated JAK2. N Engl J Med. 2013;369(25):2391-405. Available from: https:// www.ncbi.nlm.nih.gov/pmc/articles/PMC3966280/. http://www.pubmed central.nih.gov/articlerender.fcgi?artid=PMC3966280. 
10. Klampfl T, Gisslinger H, Harutyunyan AS, Nivarthi H, Rumi E, Milosevic JD, et al. Somatic mutations of calreticulin in myeloproliferative neoplasms. N Engl J med. 2013;369(25):2379-90 Available from: http://www.ncbi.nlm.nih.gov/ pubmed/24325356.

11. Vainchenker W, Kralovics R. Genetic basis and molecular pathophysiology of classical myeloproliferative neoplasms. Blood. 2017;129(6):667-79.

12. Rumi E, Pietra D, Ferretti V, Klampfl T, Harutyunyan AS, Milosevic JD, et al. JAK2 or CALR mutation status defines subtypes of essential thrombocythemia with substantially different clinical course and outcomes. Blood United States. 2014;123(10):1544-51.

13. Rumi E, Pietra D, Pascutto C, Guglielmelli P, Martínez-Trillos A, Casetti l, et al. Clinical effect of driver mutations of JAK2, CALR, or MPL in primary myelofibrosis. Blood. 2014;124(7):1062-9.

14. Aranaz P, Ormazabal C, Hurtado C, Erquiaga I, Calasanz MJ, Garcia-Delgado M, et al. A new potential oncogenic mutation in the FERM domain of JAK2 in BCR/ABL1-negative and V617F-negative chronic myeloproliferative neoplasms revealed by a comprehensive screening of 17 tyrosine kinase coding genes. Cancer Genet Cytogenet United States. 2010;199(1):1-8.

15. Trifa AP, Banescu C, Dima D, Bojan AS, Tevet M, Moldovan VG, et al. Among a panel of polymorphisms in genes related to oxidative stress, CAT-262 C>T, GPX1 Pro198Leu and GSTP1 lle105Val influence the risk of developing BCR$A B L$ negative myeloproliferative neoplasms. Hematology England. 2016; 21(9):520-5.

16. Neri A, Fracchiolla NS, Radaelli F, Boletini A, Ribera S, Migliorini C, et al. p53 tumour suppressor gene and RAS oncogenes: molecular analysis in the chronic and leukaemic phases of essential thrombocythaemia. Br J Haematol England. 1996;93(3):670-3.

17. Aviram A, Witenberg B, Shaklai M, Blickstein D. Detection of methylated ABL1 promoter in Philadelphia-negative myeloproliferative disorders. Blood Cells Mol Dis United States. 2003;30(1):100-6.

18. Kissova J, Bulikova A, Ovesna P, Bourkova L, Penka M. Increased mean platelet volume and immature platelet fraction as potential predictors of thrombotic complications in BCR/ABL-negative myeloproliferative neoplasms. Int J Hematol. Japan. 2014;100(5):429-36.

19. Kander EM, Raza S, Zhou Z, Gao J, Zakarija A, McMahon BJ, et al. Bleeding complications in BCR-ABL negative myeloproliferative neoplasms: prevalence, type, and risk factors in a single-center cohort. Int J Hematol. Japan. 2015;102(5):587-93.

20. Qin Y, Wang X, Zhao C, Wang C, Yang Y. The impact of JAK2V617F mutation on different types of thrombosis risk in patients with essential thrombocythemia: a meta-analysis. Int J Hematol Japan. 2015;102(2):170-80.

21. Kong H, Liu Y, Luo S, Li Q, Wang Q. Frequency of calreticulin (CALR) mutation and its clinical prognostic significance in essential Thrombocythemia and primary myelofibrosis: a meta-analysis. Intern Med Japan. 2016;55(15):1977-84.

22. Kourie HR, Ameye L, Paesmans M, Bron D. Improved survival of calreticulinmutated patients compared with Janus kinase 2 in primary myelofibrosis: a meta-analysis. Clin Lymphoma Myeloma Leuk United States. 2016;16(5):264-8.

23. Pei Y-Q, Wu Y, Wang F, Cui W. Prognostic value of CALR vs. JAK2V617F mutations on splenomegaly, leukemic transformation, thrombosis, and overall survival in patients with primary fibrosis: a meta-analysis. Ann Hematol. Germany. 2016;95(9):1391-8.

24. Lengfelder E. Diagnosis and therapy of polycythemia vera in the era of JAK2. Dtsch med Wochenschr. Germany. 2013;138(7):331-6.

25. Anderson LA, Duncombe AS, Hughes M, Mills ME, Wilson JC, McMullin MF. Environmental, lifestyle, and familial/ethnic factors associated with myeloproliferative neoplasms. Am J Hematol United States. 2012;87(2): 175-82.

26. Moher D, Liberati A, Tetzlaff J, Altman DG, Group TP. Preferred Reporting Items for Systematic Reviews and Meta-Analyses: The PRISMA Statement. 2009;6(7):e1000097. https://doi.org/10.1371/journal.pmed.1000097.

27. Schlosser RW, Wendt O, Bhavnani S, Nail-chiwetalu B. Review use of information-seeking strategies for developing systematic reviews and engaging in evidence-based practice : the application of traditional and comprehensive pearl growing. A review. 2006.

28. von Elm E, Altman DG, Egger M, Pocock SJ, Gotzsche PC, Vandenbroucke JP. The strengthening the reporting of observational studies in epidemiology (STROBE) statement: guidelines for reporting observational studies. J Clin Epidemiol United States. 2008;61(4):344-9.

29. Hsu H-C, Tan L-Y, Au L-C, Lee Y-M, Lieu C-H, Tsai W-H, et al. Detection of bcr-abl gene expression at a low level in blood cells of some patients with essential thrombocythemia. J Lab Clin Med United States. 2004;143(2):125-9.
30. Jelinek J, Oki Y, Gharibyan V, Bueso-Ramos C, Prchal JT, Verstovsek S, et al. JAK2 mutation $1849 \mathrm{G}>\mathrm{T}$ is rare in acute leukemias but can be found in CMML, Philadelphia chromosome-negative CML, and megakaryocytic leukemia. Blood. United States. 2005;106(10):3370-3.

31. Jost E, Do O N, Dahl E, Maintz CE, Jousten P, Habets $L$, et al. Epigenetic alterations complement mutation of JAK2 tyrosine kinase in patients with BCR/ABL-negative myeloproliferative disorders. Leukemia. England; 2007; 21(3):505-510.

32. Zhang S, Li W, Song J, Xu W, Qiu H, Li J. The investigation of JAK2 V617F point mutation in myeloproliferative disorders by allele-specific polymerase chain reaction in combination with sequence analysis. Zhonghua Yi Xue Za Zhi. China. 2007;87(30):2109-12.

33. Najfeld V, Cozza A, Berkofsy-Fessler W, Prchal J, Scalise A. Numerical gain and structural rearrangements of JAK2, identified by FISH, characterize both JAK2617V>F-positive and -negative patients with Ph-negative MPD, myelodysplasia, and B-lymphoid neoplasms. Exp Hematol Netherlands. 2007;35(11):1668-76.

34. Suzuki R, Onizuka M, Kojima M, Shimada M, Tsuboi K, Ogawa Y, et al. Infrequent hypermethylation of WIF-1 promoter in BCR/ABL-negative myeloproliferative disorders. Tokai J Exp Clin Med Japan. 2007;32(4):131-5.

35. Xu W, Li J-Y, Xia J, Zhang S-J, Fan L, Qiao C. MPL W515L mutation in Chinese patients with myeloproliferative diseases. Leuk Lymphoma. England. 2008;49(5):955-8.

36. Lucia E, Martino B, Mammi C, Vigna E, Mazzone C, Gentile M, et al. The incidence of JAK2 V617F mutation in bcr/abl-negative chronic myeloproliferative disorders: assessment by two different detection methods. Leuk Lymphoma England. 2008;49(10):1907-15.

37. Tefferi A, Sirhan S, Sun Y, Lasho T, Finke CM, Weisberger J, et al. Oligonucleotide array CGH studies in myeloproliferative neoplasms: comparison with JAK2V617F mutational status and conventional chromosome analysis. Leuk Res. England. 2009;33(5):662-4.

38. Tefferi A, Pardanani A, Lim K-H, Abdel-Wahab O, Lasho TL, Patel J, et al. TET2 mutations and their clinical correlates in polycythemia vera, essential thrombocythemia and myelofibrosis. Leukemia England. 2009;23(5):905-11.

39. Tripodi J, Hoffman R, Najfeld V, Weinberg R. Frequency of heterozygous TET2 deletions in myeloproliferative neoplasms. Cancer Manag Res New Zealand. 2010;2:219-23.

40. Chen X, Qi X, Tan Y, Xu Z, Xu A, Zhang L, et al. Detection of MPL exon10 mutations in 103 Chinese patients with JAK2V617F-negative myeloproliferative neoplasms. Blood Cells Mol Dis. United States. 2011;47(1):67-71.

41. Toyama K, Karasawa M, Yokohama A, Mitsui T, Uchiumi H, Saitoh T, et al. Differences in the JAK2 and MPL mutation status in the cell lineages of the bcr/abl-negative chronic myeloproliferative neoplasm subtypes. Intern Med. Japan. 2011;50(21):2557-61.

42. Benmoussa A, Dehbi H, Fehri S, Quessar A, Nadifi S. JAK2-V617F mutation in Moroccan patients with myeloproliferative disorders: contribution, diagnosis and therapeutic prospects. Pathol Biol (Paris). France. 2011;59(4):e89-92.

43. da Silva RR, Domingues Hatzlhofer BL, Machado CG, Lima AS, de Albuquerque DM, dos Santos MNN, et al. JAK2 V617F mutation prevalence in myeloproliferative neoplasms in Pernambuco, Brazil. Genet Test Mol Biomarkers. United States. 2012;16(7):802-5.

44. Zhang X, Maimaitili Y, Li Y, An L, Mao M, Fu L, et al. Detection and clinical significance of JAK2 V617F mutation in Chinese and Uyghur patients with chronic myeloproliferative in Xinjiang. Zhonghua Xue ye Xue Za Zhi. China. 2012;33(12):1020-3.

45. Ho C-L, Wu Y-Y, Hung H-M, Chang P-Y, Kao W-Y, Chen Y-C, et al. Rapid identification of heterozygous or homozygous JAK2(V617F) mutations in myeloproliferative neoplasms using melting curve analysis. J Formos Med Assoc Singapore. 2012;111(1):34-40.

46. Schnittger S, Bacher U, Eder C, Dicker F, Alpermann T, Grossmann V, et al. Molecular analyses of 15,542 patients with suspected BCR-ABL1-negative myeloproliferative disorders allow to develop a stepwise diagnostic workflow. Haematologica. 2012;97(10):1582-5.

47. Pagliarini-e-Silva S, Santos BC, Pereira EM, Ferreira ME, Baraldi EC, Sell AM, et al. Evaluation of the association between the JAK2 46/1 haplotype and chronic myeloproliferative neoplasms in a Brazilian population. Clinics (Sao Paulo). Brazil. 2013;68(1):5-9.

48. Patriarca A, Colaizzo D, Tiscia G, Spadano R, Di Zacomo S, Spadano A, et al. TET2 mutations in Ph-negative myeloproliferative neoplasms: identification of three novel mutations and relationship with clinical and laboratory findings. Biomed Res Int. United States. 2013;2013:929840. 
49. Kim H-R, Choi H-J, Kim Y-K, Kim H-J, Shin J-H, Suh S-P, et al. Allelic expression imbalance of JAK2 V617F mutation in BCR-ABL negative myeloproliferative neoplasms. PLoS One United States. 2013;8(1):e52518.

50. Wu Z, Zhang $X, X u X, C h e n ~ Y, H u T$, Kang Z, et al. The mutation profile of JAK2 and CALR in Chinese Han patients with Philadelphia chromosomenegative myeloproliferative neoplasms. J Hematol Oncol. England. 2014;7:48.

51. Payzin KB, Savasoglu K, Alacacioglu I, Ozdemirkiran F, Mutlu BB, Bener S, et al. JAK2 V617F mutation status of 232 patients diagnosed with chronic myeloproliferative neoplasms. Clin Lymphoma Myeloma Leuk. United States. 2014;14(6):525-33.

52. Macedo LC, Santos BC, Pagliarini-e-Silva S, Pagnano KBB, Rodrigues C, Quintero FC, et al. JAK2 46/1 haplotype is associated with JAK2 V617F-positive myeloproliferative neoplasms in Brazilian patients. Int J Lab Hematol England. 2015;37(5):654-60.

53. Ouyang Y, Qiao C, Wang J, Xiao L, Zhang S. Analysis of CALR, JAK2 and MPL gene mutations in $B C R-A B L$ negative myeloproliferative neoplasms. Zhonghua Yi Xue Za Zhi. China. 2015;95(18):1369-73.

54. Mahjoub S, Baccouche H, Sahnoun M, Kaabi H, Manai Z, Slama H, et al. The JAK2 mutation in myeloproliferative disorders: a predictive factor of thrombosis. Tunis med. Tunisia. 2015;93(7):474-7.

55. Jaradat SA, Khasawneh R, Kamal N, Matalka I, Al-Bishtawi M, Al-Sweedan S, et al. Analysis of JAK2V617F mutation in Jordanian patients with myeloproliferative neoplasms. Hematol Oncol Stem Cell Ther. England. 2015;8(4):160-6.

56. Labastida-Mercado N, Galindo-Becerra S, Garces-Eisele J, Colunga-Pedraza P, Guzman-Olvera V, Reyes-Nunez V, et al. The mutation profile of JAK2, MPL and CALR in Mexican patients with Philadelphia chromosome-negative myeloproliferative neoplasms. Hematol Oncol Stem Cell Ther England. 2015; 8(1):16-21.

57. Duangnapasatit B, Rattarittamrong E, Rattanathammethee T, Hantrakool S, Chai-Adisaksopha C, Tantiworawit A, et al. Clinical manifestations and risk factors for complications of Philadelphia chromosome-negative myeloproliferative neoplasms. Asian Pac J Cancer Prev Thailand. 2015;16(12):5013-8.

58. Geduk A, Atesoglu EB, Tarkun P, Mehtap O, Hacihanefioglu A, Demirsoy ET, et al. The role of beta-catenin in Bcr/Abl negative myeloproliferative neoplasms: An Immunohistochemical study. Clin Lymphoma Myeloma Leuk. United States. 2015;15(12):785-9.

59. Lin Y, Liu E, Sun Q, Ma J, Li Q, Cao Z, et al. The prevalence of JAK2, MPL, and CALR mutations in Chinese patients with BCR-ABL1-negative myeloproliferative neoplasms. Am J Clin Pathol. 2015;144(1):165-71.

60. Berzoti-Coelho MG, Ferreira AF, de Souza NN, Pinto MT, Junior MCR, Simoes BP, et al. The expression of death inducer-obliterator (DIDO) variants in myeloproliferative neoplasms. Blood Cells Mol Dis. United States. 2016;59:25-30.

61. Macedo LC, de Cesare QF, Pagliari-E-Silva S, Pagnano KBB, Rodrigues C, de Alencar JB, et al. Association of TNF polymorphisms with JAK2 (V617F) myeloproliferative neoplasms in Brazilian patients. Blood Cells Mol Dis United States. 2016;57:54-7.

62. Didone A, Nardinelli L, Marchiani M, Ruiz ARL, de Lima Costa AL, Lima IS, et al. Comparative study of different methodologies to detect the JAK2 V617F mutation in chronic BCR-ABL1 negative myeloproliferative neoplasms. Pract Lab Med Netherlands. 2016;4:30-7.

63. Xu J, Xu Z, Wang J, Li B, Sun X, Qin T, et al. The assessment of symptomatic burden among Ph/BCR- ABL negative myeloproliferative neoplasm patients. Zhonghua Xue ye Xue Za Zhi. China. 2016;37(1):26-9.

64. McFarland DC, Polizzi H, Mascarenhas J, Kremyanskaya M, Holland J, Hoffman R. Psychological Symptoms Among Patients With BCR-ABLNegative Myeloproliferative Neoplasms. J Natl Compr Canc Netw. United States. 2016;14(12):1563-70.

65. Wang JC, Kundra A, Andrei M, Baptiste S, Chen C, Wong C, et al. Myeloidderived suppressor cells in patients with myeloproliferative neoplasm. Leuk Res. England. 2016;43:39-43.

66. Gardner J-A, Peterson JD, Turner SA, Soares BL, Lancor CR, Dos Santos LL, et al. Detection of CALR mutation in clonal and nonclonal hematologic diseases using fragment analysis and next-generation sequencing. Am J Clin Pathol England. 2016;146(4):448-55.

67. Delic S, Rose D, Kern W, Nadarajah N, Haferlach C, Haferlach T, et al. Application of an NGS-based 28-gene panel in myeloproliferative neoplasms reveals distinct mutation patterns in essential thrombocythaemia, primary myelofibrosis and polycythaemia vera. $\mathrm{Br} \mathrm{J}$ Haematol. 2016;175(3):419-26.
68. Orvain C, Luque Paz D, Dobo I, Cottin L, Le Calvez G, Chauveau A, et al. Circulating $\mathrm{Cd} 34+$ cell count differentiates primary myelofibrosis from other Philadelphia-negative myeloproliferative neoplasms: a pragmatic study. Ann Hematol. 2016:95(11):1819-23.

69. Goel S, Paoli C, lurlo A, Pereira A, Efficace F, Barbui T, et al. Socioeconomic burden of participation in clinical trials in patients with myeloproliferative neoplasms. Eur J Haematol. England. 2017;99(1):36-41.

70. Smaili W, Doubaj Y, Laarabi FZ, Lyahyai J, Kerbout M, Mikdame M, et al. CALR gene mutational profile in myeloproliferative neoplasms with nonmutated JAK2 in Moroccan patients: a case series and germline in-frame deletion. Curr Res Transl Med France. 2017;65(1):15-9.

71. Gadomska G, Stankowska K, Boinska J, Slusarz R, Tylicka M, Michalska M, et al. VEGF-A, sVEGFR-1, and sVEGFR-2 in BCR-ABL negative myeloproliferative neoplasms. Medicina (Kaunas). Netherlands. 2017;53(1):34-9.

72. Yildiz I, Yokus O, Gedik H. Janus kinase 2 mutations in cases with BCR-ABLnegative chronic myeloproliferative disorders from Turkey. Avicenna J Med India. 2017;7(1):28-31.

73. Li MY, Chao HY, Sun AN, Qiu HY, Jin ZM, Tang XW, et al. Clinical significance of JAK2CALR and MPL gene mutations in 1648 Philadelphia chromosome negative myeloproliferative neoplasms patients from a single center. Zhonghua Xue Ye Xue Za Zhi. 2017;38(4):295-300.

74. Misawa K, Yasuda H, Araki M, Ochiai T, Morishita S, Shirane S, et al. Mutational subtypes of JAK2 and CALR correlate with different clinical features in Japanese patients with myeloproliferative neoplasms. Int J Hematol. 2018;107(6):673-80.

75. Gango A, Mozes R, Boha Z, Kajtar B, Timar B, Kiraly PA, et al. Quantitative assessment of JAK2 V617F and CALR mutations in Philadelphia negative myeloproliferative neoplasms. Leuk Res. 2018;65:42-8.

76. Lim Y, Lee JO, Bang SM. Incidence, Survival and Prevalence Statistics of Classical Myeloproliferative Neoplasm in Korea. J Korean Med Sci. Korea (South). 2016:31(10):1579-85

77. Roaldsnes C, Holst R, Frederiksen H, Ghanima W. Myeloproliferative neoplasms: trends in incidence, prevalence and survival in Norway. Eur J Haematol England. 2017;98(1):85-93.

78. Mughal TI, Gotlib J, Mesa R, Koschmieder S, Khoury HJ, Cortes JE, et al. Recent advances in the genomics and therapy of BCR/ABL1-positive and -negative chronic myeloproliferative neoplasms. Leuk Res England. 2018;67: 67-74.

79. Sabattini E, Bacci F, Sagramoso C, Pileri SA. WHO classification of tumours of haematopoietic and lymphoid tissues in 2008: an overview. Pathologica. Italy. 2010;102:83-7.

80. Griesshammer M, Sadjadian P. The BCR-ABL1-negative myeloproliferative neoplasms: a review of JAK inhibitors in the therapeutic armamentarium. Expert Opin Pharmacother England. 2017;18(18):1929-38.

81. Lundberg P, Karow A, Nienhold R, Looser R, Hao-shen H, Nissen I, et al. Clonal evolution and clinical correlates of somatic mutations in myeloproliferative neoplasms. Blood. 2014;123(14):2220-8. https://doi.org/10.1182/blood-2013-11537167.

82. Bench AJ, White HE, Foroni L, Godfrey AL, Gerrard G, Akiki S, et al. Molecular diagnosis of the myeloproliferative neoplasms: UK guidelines for the detection of JAK2 V617F and other relevant mutations. Br J Haematol. 2013;160(1):25-34

83. Lavi N. Calreticulin Mutations in Myeloproliferative Neoplasms. Rambam Maimonides Med J. 2014;5(4):e0035. https://doi.org/10.5041/RMMJ.10169.

84. Kralovics R, Passamonti F, Buser AS, Teo S-S, Tiedt R, Passweg JR, et al. A gain-of-function mutation of JAK2 in myeloproliferative disorders. N Engl J Med. 2005;352(17):1779-90.

85. Levine RL, Wadleigh M, Cools J, Ebert BL, Wernig G, Huntly BJP, et al. Activating mutation in the tyrosine kinase JAK2 in polycythemia vera, essential thrombocythemia, and myeloid metaplasia with myelofibrosis. Cancer Cell. 2005;7(4):387-97.

86. Saeidi K. Critical reviews in oncology / hematology myeloproliferative neoplasms: current molecular biology and genetics. Crit rev Oncol / Hematol. Elsevier Ireland Ltd. 2016;98:375-89 Available from: https://doi. org/10.1016/j.critrevonc.2015.11.004.

87. Vannucchi AM, Antonioli E, Guglielmelli P, Pancrazzi A, Guerini V, Barosi G, et al. Characteristics and clinical correlates of MPL 515W>L/K mutation in essential thrombocythemia. Blood. 2008;112(3):844-7.

88. Beer PA, Campbell PJ, Scott LM, Bench AJ, Erber WN, Bareford D, et al. MPL mutations in myeloproliferative disorders: analysis of the PT-1 cohort. Blood. 2008;112(1):141-9. 
89. Haider M, Elala YC, Gangat N, Hanson CA, Tefferi A. MPL mutations and palpable splenomegaly are independent risk factors for fibrotic progression in essential thrombocythemia. Blood cancer journal. United States. 2016; 6:e487.

90. Szuber N, Hanson CA, Lasho TL, Finke C, Ketterling RP, Pardanani A, et al. MPL-mutated essential thrombocythemia: a morphologic reappraisal. Blood cancer journal. United States. 2018:8:121.

\section{Publisher's Note}

Springer Nature remains neutral with regard to jurisdictional claims in published maps and institutional affiliations.

Ready to submit your research? Choose BMC and benefit from:

- fast, convenient online submission

- thorough peer review by experienced researchers in your field

- rapid publication on acceptance

- support for research data, including large and complex data types

- gold Open Access which fosters wider collaboration and increased citations

- maximum visibility for your research: over $100 \mathrm{M}$ website views per year

At BMC, research is always in progress.

Learn more biomedcentral.com/submissions 